\title{
Synthetic progestagen-oestrogen preparations and endometrial morphology ${ }^{1}$
}

\author{
WILLIAM B. OBER \\ From the New York Fertility Institute, New York, N.Y., and \\ Knickerbocker Hospital, New York, N.Y.
}

SYNOPSIS 19-nor steroids in high and medium dosage in continuous or cyclic combined regimeng with oestrogen produce an endometrium characterized by hyperinvoluted glands, a prominenito predecidual reaction, suppressed arterioles, and dilated venules. When daily dosage is decreased t $\overrightarrow{\Theta_{0}}$ $2.0 \mathrm{mg}$. or less, the endometrium is composed of hyperinvoluted glands in an inert stroma; predecid ual reactions are weak and infrequent; venules are rarely dilated, but spiral arterioles are suppressed?

$17-\alpha$-Acetoxyprogesterone derivatives in high and medium dosage given in a cyclic combined regimen with oestrogen produce similar but less intense effects to the 19-nor steroids. When given if cyclic sequential regimen, they produce an early secretory endometrium closely resembling normaf patterns, chronologically retarded by about five days; in some instances a regressing, undatable secretory pattern is found, but predecidual response is minimal, and dilated venules are not seen. $:$

19-nor steroids in medium dosage given for 20 days without added oestrogen produce a late secreפ tory endometrium with unpredictable variation from patient to patient and even from site to site within the same endometrium.

Inhibition of the development of spiral arterioles is a common denominator in all progestagen⿳亠丷⿵冂丶 oestrogen regimens. Modification of this element within the target tissue may be decisive for the morphogenesis of later vascular and stromal changes.

Using synthetic progestagen-oestrogen regimens, endometrial gland secretion appears only afte progestagen, whether given ab initio concomitantly with oestrogen or begun after a phase of oestrog gen priming. Secretory vacuoles become evident about four to five days after progestagen is adminis stered. The role of progestagen in secretion is interpreted as an indirect effect whereas its role in the development of decidual-like changes is construed as direct.

Current clinical use of synthetic progestagens, usually in combination or in sequence with synthetic oestrogens, is predominantly concerned with control of ovulation, but these preparations are also used in a variety of gynaecological conditions such as endometriosis, dysmenorrhoea, dysfunctional bleeding, and, somewhat paradoxically, in endocrine infertility. A number of different steroid molecules have been developed and are available; others are being tested in clinical trials, and still others are being newly synthesized and their properties tested in animals. Two main classes of synthetic progestagen in current use are those derived from 19-nor-testosterone and those derived from 17- $a$-acetoxyprogesterone. The exposi-

'Presented at the meeting of the Pathological Society of Great Britain and Ireland and the Norwegian Pathological Society on 8 July 1965 at Dundee.

Received for publication 7 October 1965. tory purpose of this communication is to demon strate the differences in endometrial morpholog with these hormones in high, medium, and low dosage, with and without added oestrogen, and im differing schedules of administration with reference to the menstrual cycle. The practical objects of this study are to permit the gynaecologist to select the type of endometrial morphology he wishes his patient to develop after treatment and to furnish a guide for the pathologist in evaluating the degree of success should the gynaecologist be thoughtful enough to inform the pathologist of the details and purpose of the antecedent medication.

The salient features of endometrial resonse can be illustrated with reference to five synthetic progestag ens, including three 19-nor- steroids and two 17-ce acetoxyprogesterone derivatives. These compounds are listed in Table I, together with the number of 
TABLE I

\begin{tabular}{|c|c|c|c|c|}
\hline Progestagen & $\begin{array}{l}\text { No. of } \\
\text { Biopsies }\end{array}$ & $\begin{array}{l}\text { No. of } \\
\text { Patients }\end{array}$ & $\begin{array}{l}\text { No. of } \\
\text { Cycles }\end{array}$ & $\begin{array}{l}\text { Dosage(s) of Progestagen and } \\
\text { Added Oestrogen } \\
(\mathrm{mg} .)\end{array}$ \\
\hline Norethynodrel $^{1}$ & 63 & 20 & 36 & $\begin{array}{l}9.85+0.15 \text { mestranol* } \\
5.0+0.075 \text { mestranol }\end{array}$ \\
\hline Ethynodiol diacetate ${ }^{2}$ & 58 & 26 & 39 & $1.0+0.1$ mestranol \\
\hline WY $-3707^{3}$ & 21 & 10 & 14 & $5 \cdot 0$ - no oestrogen \\
\hline WY-3707 & 61 & 24 & 59 & $0.5+0.05 \mathrm{EE}^{* *}$ \\
\hline Medroxyprogesterone & 45 & 15 & 33 & $\begin{array}{l}10.0+0.05 \mathrm{EE} \\
5.0+0.05 \mathrm{EE}\end{array}$ \\
\hline Chlormadinone $^{\mathrm{s}}$ & $\begin{array}{r}55 \\
303\end{array}$ & $\begin{array}{r}24 \\
119\end{array}$ & $\begin{array}{r}49 \\
230\end{array}$ & $2.0+0.08$ mestranol sequential schedule \\
\hline
\end{tabular}

${ }^{1} 17-\alpha$-ethynyl-17- $\beta$-hydroxy-3-oxo- $\Delta-5$ (10)-estrene. (Enovid, Conovid). G.D. Searle Co.

217- $\alpha$-ethynyl-4-estrene-3 $\beta, 17 \beta$-diol diacetate. (Ovulen, Metrulen). G. D. Searle Co.

${ }^{3} \pm 13 \beta$-ethyl-17- $\alpha$-ethynyl-17- $\beta$ hydroxygon-4-en-3-one. (Investigational) Wyeth Laboratories.

46- $\alpha$-methyl-17- $\alpha$-acetoxyprogesterone acetate. (Provera, Provest). Upjohn Co.

56-chloro-6-dehydro-17- $\alpha$-acetoxyprogesterone. (Sequenyl). Syntex Laboratories.

*Ethinyl oestradiol-3 methyl ether

**Ethinyl oestradiol.

biopsies examined, the number of patients and cycles in which observations were made, and information regarding dosage of the progestagen and oestrogen used. All compounds were administered orally. The subjects included in this report were judged to be ovulating and menstruating with reasonable regularity by conventional criteria. Excluded from this report are observations in women with one or another of the anovulatory syndromes, as their endometrial response is more variable, and our experience insufficient to permit classification and generalization.

Material for histopathological study was obtained by endometrial biopsy. Tissues were fixed immediately in neutral buffered formalin and stained with haematoxylin and eosin as well as by Schiff's periodic acid reagent for mucopolysaccharides and glycoproteins. The limitations of this method are that only superficial layers of the uterine mucosa are examined and that, given the variability of endometrial response from locus to locus, a few bioptic fragments need not necessarily be representative of the mucosa as a whole. To some extent the latter limitation is compensated for by the number of biopsies examined. Endometrial biopsy was performed at various intervals of medication to permit evaluation of the sequence of changes. In some subjects as many as four biopsies were obtained during one treatment cycle. This technique and its advantages have already been described (Roland, Decker, Clyman, and Ober, 1965).

\section{OBSERVATIONS}

The endometrial response to exogenous steroids varies with three interdependent factors, dosage, time (duration), and the point in the menstrual cycle when the stimulus is applied. Three different dosage schedules are commonly used when synthetic progestagens are administered: (1) continuous medication, i.e., daily administration of the hormone at a stated level (which may be increased stepwise), as in the management of endometriosis or any other condition in which long-term suppression of ovarian activity is desirable; (2) cyclic combined medication, in which the progestagen-oestrogen preparation is given in a stated dose, usually for 20 days, usually beginning on the fifth or sixth day after the onset of flow; (3) cyclic sequential medication, in which oestrogen-priming is carried out for 10 days, starting of the fifth day of the cycle, followed by 10 days of progestagen-oestrogen medication.

NORETHYNODREL Norethynodrel and its isomer, norethindrone, are the progestagens most widely used, and their effects on the endometrium are well documented in previous reports (Ryan, Craig, and Reid, 1964; Cronqvist and Kullander, 1961 ; Roland et al., 1964). The basic progestational effect of norethynodrel is demonstrated by its capacity to induce a predecidual reaction in the endometrial stroma of a castrate (Figs. 1 and 2), who received $9.85 \mathrm{mg}$. daily with $0 \cdot 15 \mathrm{mg}$. mestranol for 20 days beginning five days after the onset of induced oestrogen-withdrawal bleeding. In such endometria a mild degree of ectasia of venules is also noted. With higher dosage over a longer interval the decidua-like reaction is more intense and glands are hyperinvoluted (Figs. 3 and 4), as in the endometria of subjects receiving norethynodrel with oestrogen on a continuous schedule with daily doses increased to $28.55 \mathrm{mg}$. to control breakthrough bleeding.

When norethynodrel is administered in cyclic combined schedules for ovulation control at either $9.85 \mathrm{mg}$. or $5 \mathrm{mg}$. with mestranol for 20 days, an initial phase of precocious glandular secretion occurs 


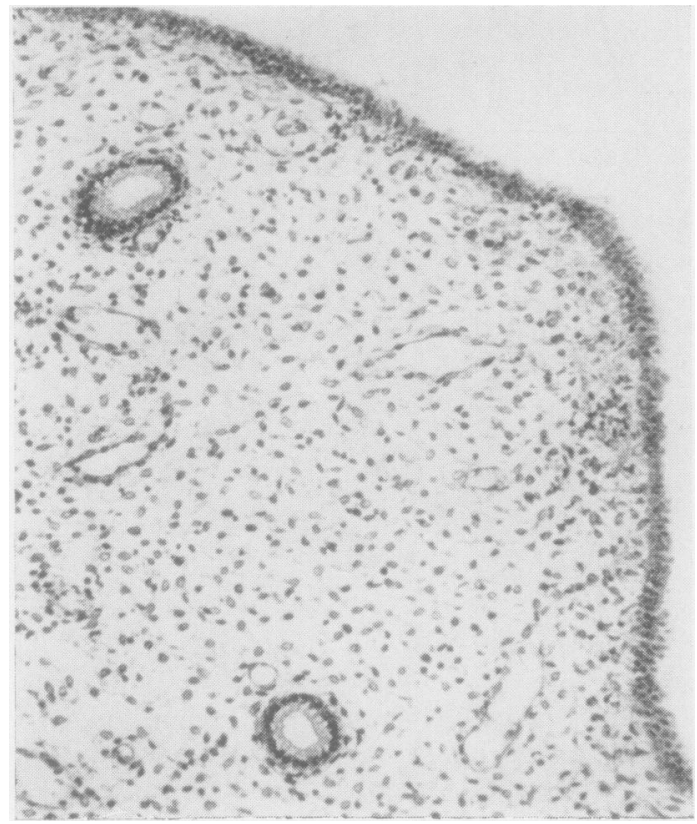

FIG. 1.

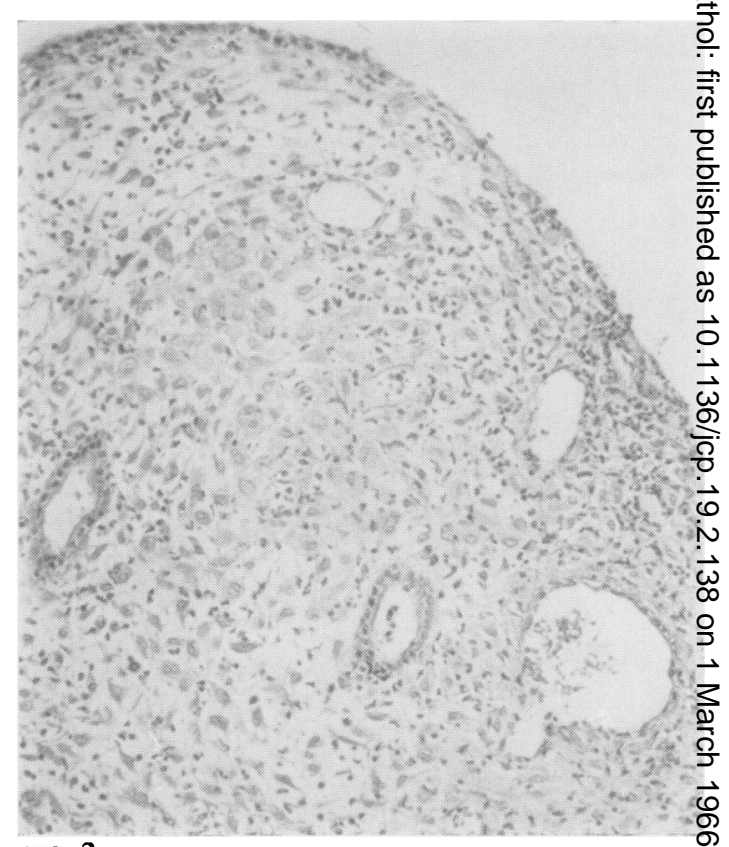

FIG. 2.

FIG. 1. Pre-treatment endometrial biopsy in a 21-year-old castrate showing atrophic endometrium. (Haematoxylin ang eosin $\times$ 100.)

FIG. 2. Same patient as in Fig. 1 after 20 days of norethynodrel at $9.85 \mathrm{mg}$. daily plus mestranol at $0 \cdot 15 \mathrm{mg}$. daily shov ing a predecidual reaction in the stroma and moderately dilated venules. (Haematoxy'in and eosin $\times 100$.)

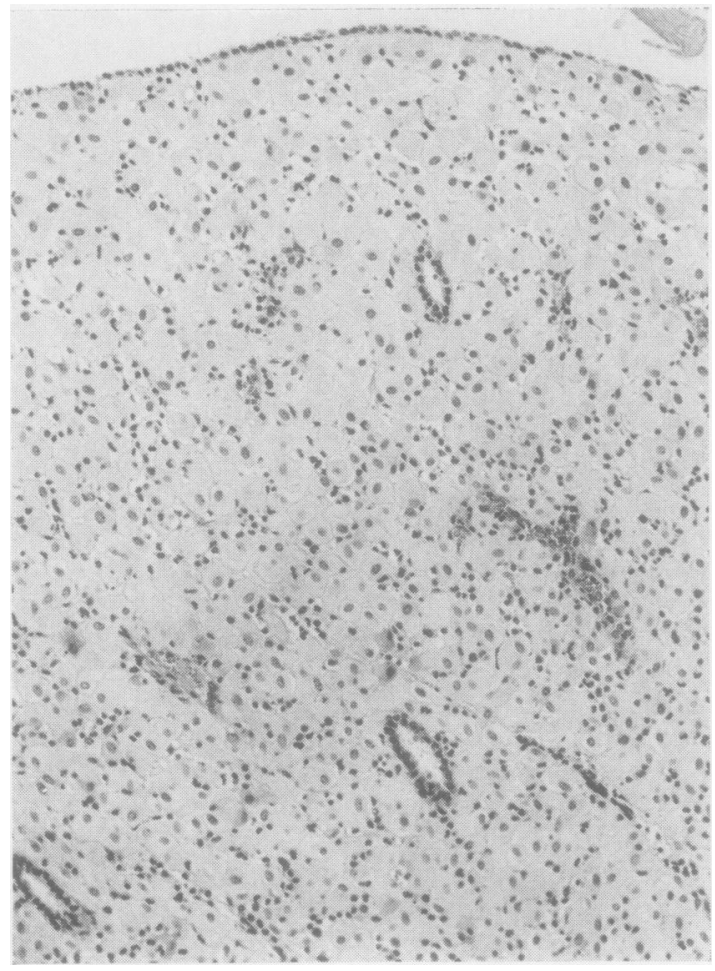

FIG. 3 .

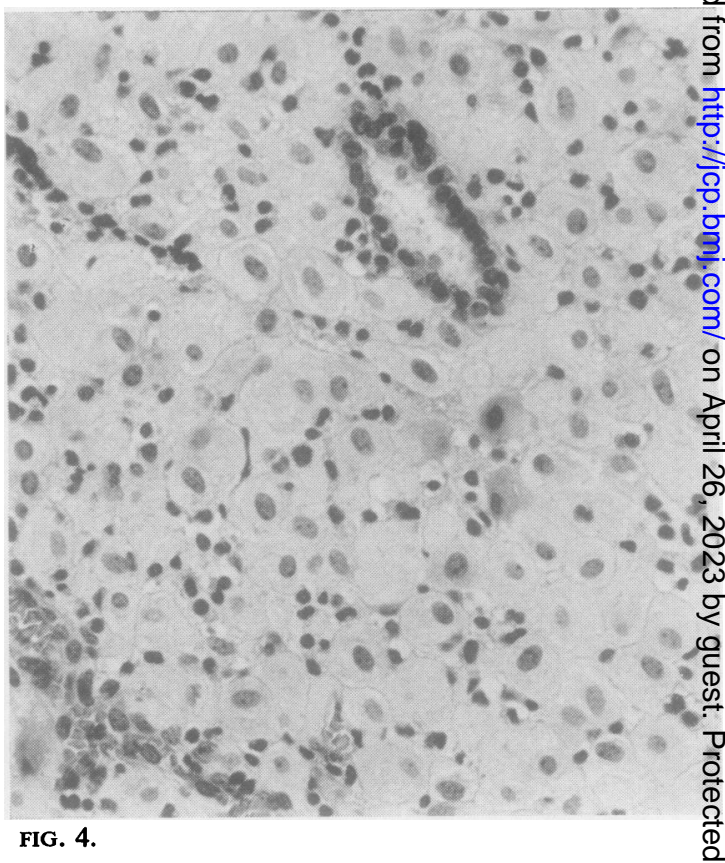

FIGS. 3 and 4. Endometrium in a patient with endometriosis after nine months of continuous treatment with norethynodrel with mestranol at doses up to $30 \mathrm{mg}$. daily, showigg hyperinvoluted glands and intense decidua-like stromal response, and (Fig. 4) detail of Figure 3. (Both haematox) lin and eosin $\times 100$.) 


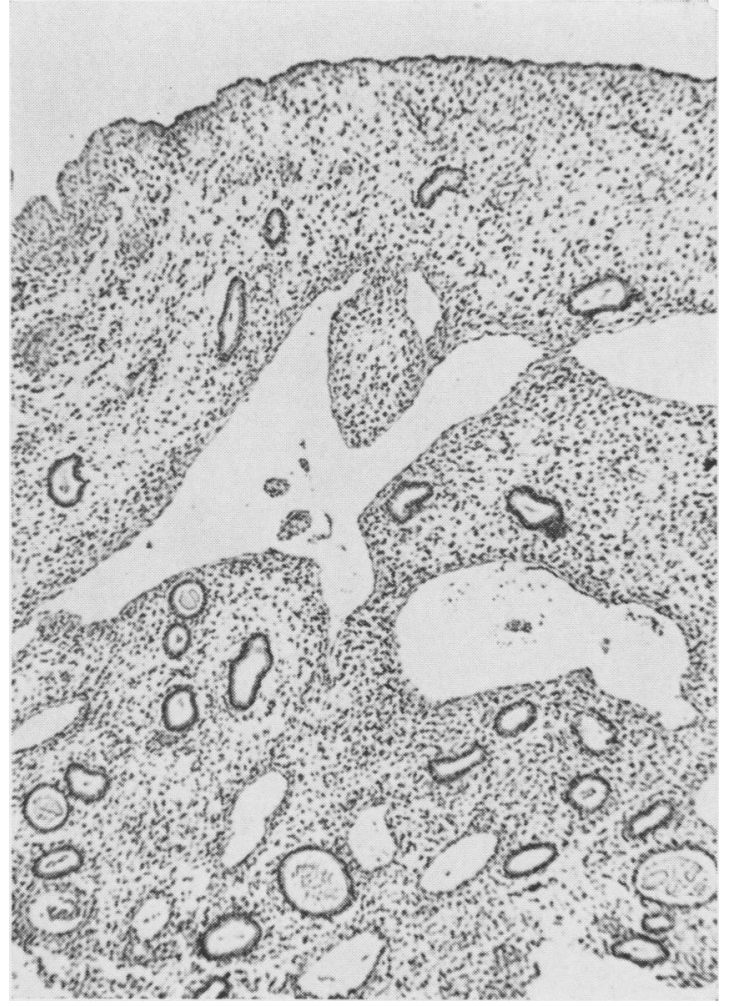

FIG. 5.

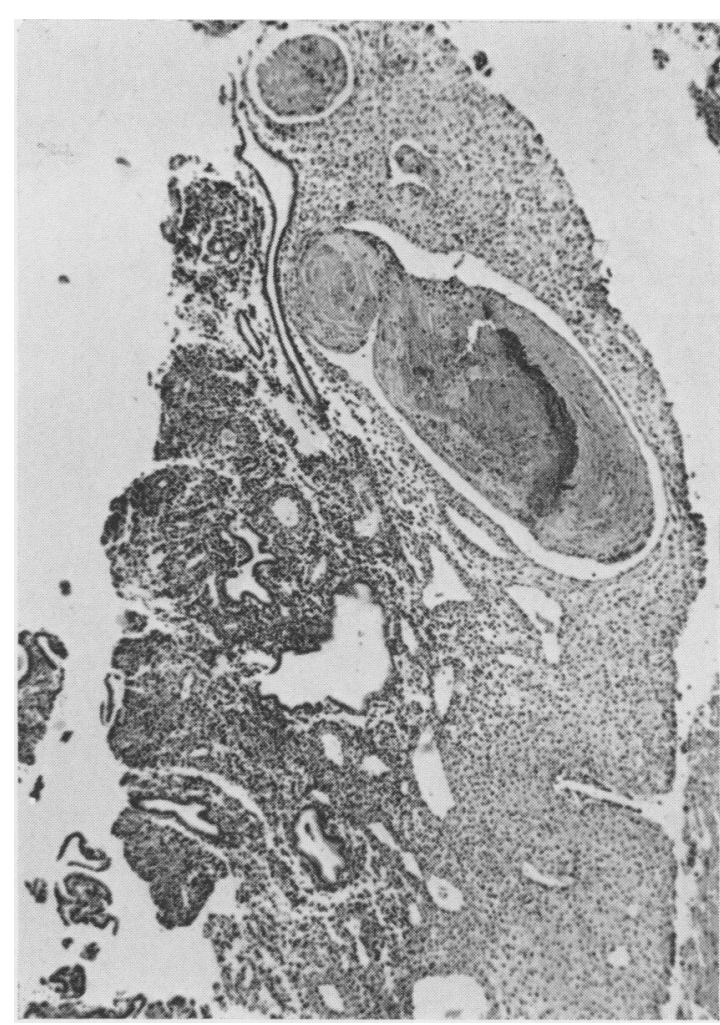

FIG. 6.

FIG. 5. Endometrial biopsy in a subject with regular menses after norethynodrel with mestranol at $10 \mathrm{mg}$. daily for 20 days showing hyperinvoluted glands, predecidual transformation of the stroma, pronounced ectasia of venules, and suppressed spiral arterioles. (Haematoxylin and eosin $\times 100$.

FIG. 6. Endometrial biopsy in a subject with regular menses after norethynodrel with mestranol at 10 mg. daily for 20 days showing same features as Fig. 5 but with thrombosis of the dilated venules. (Haematoxylin and eosin $\times 40$.)

about five days after medication is begun. Secretory activity regresses rapidly, the rate varying somewhat from subject to subject. Predecidual changes develop in the stroma after about 15 days of medication, and are predominant at the end of the 20-day treatment cycle. There is little difference in the extent of the predecidual transformation between the $\mathbf{9 . 8 5}$ $\mathrm{mg}$. dose level and the $5.0 \mathrm{mg}$. dose. Development of spiral arterioles is almost uniformly inhibited. In about half the cases examined, dilated sinusoidal venules are seen, most prominently just beneath the surface epithelium (Fig. 5). Such ectatic venules are often wider in calibre than the hyperinvoluted glands, and thrombosis of these abnormal channels (Fig. 6) is probably the mechanism whereby breakthrough bleeding develops.

We have not had the opportunity to study the effects of norethynodrel at a $2.5 \mathrm{mg}$. daily dose, nor have we employed it in cyclic sequential regimens.
ETHYNODIOL DIACETATE This 19-nor steroid has been studied extensively in a wide range of doses $(0.1 \mathrm{mg}$. to $5.0 \mathrm{mg}$.) in cyclic combined schedules by Morley (1965) using mestranol as the concomitant oestrogen. Stable effects on endometrial morphology are obtained using $1.0 \mathrm{mg}$. or $2.0 \mathrm{mg}$. of ethynodiol diacetate with $0 \cdot 1 \mathrm{mg}$. of mestranol. The most common pattern in biopsies taken after 20 days of medication consists of glands of small calibre lined by a relatively low epithelium, embedded in a loose, naked nucleus type of stroma (Fig. 7). Some traces of a transient, antecedent phase of gland secretion are usually detectable. A degree of stromal oedema is present in almost every case. About $15 \%$ of the biopsies show a predecidual reaction of variable intensity, occasionally to the extent of forming a pseudo-decidual plaque. Proliferation of spiral arterioles is inhibited, but the venules are often dilated. 


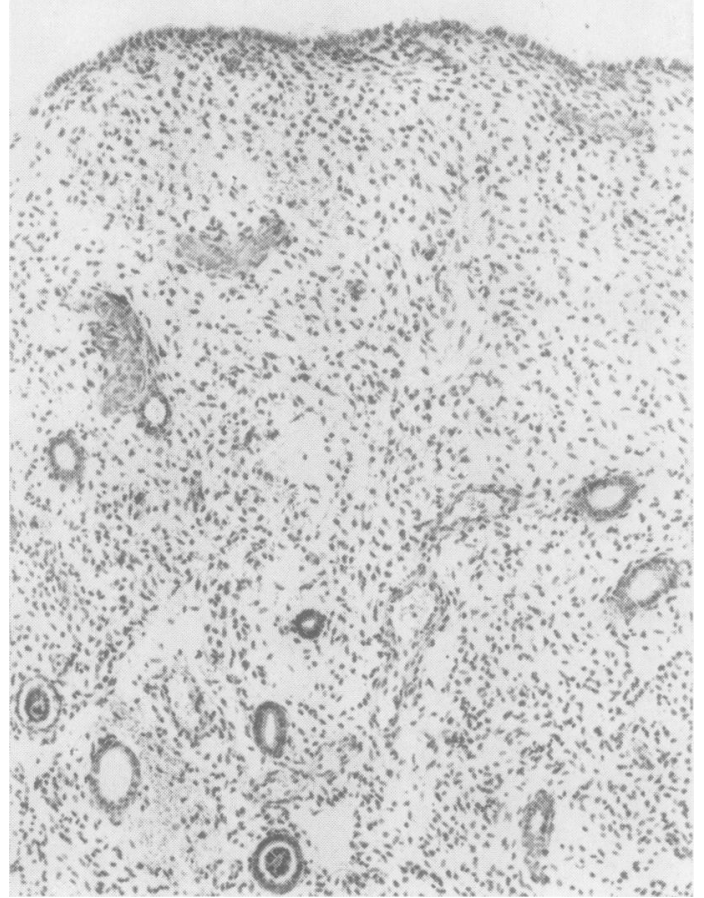

FIG. 7 .

FIG. 7. Endometrial biopsy after ethynodiol diacetate $1 \cdot 0$ m.g. daily with mestranol $0.1 \mathrm{mg}$. for 20 days showing small glands lined by low epithelium in an inert stroma with poorly developed vessels. (Haematoxylin and eosin $\times 100$.)

FIG. 8. Endometrial biopsy after WY-3707 $5 \mathrm{mg}$. daily for 20 days without oestrogen, showing glands of average calibre with regressing secretion but no predecidual reaction. (Haematoxylin and eosin $\times 100$.)

FIG. 9. Same biopsy as in Fig. 8 showing another area with small glands and an intense predecidual reaction. (Haematoxylin and eosin $\times$ 100.)
FIG. 8 .
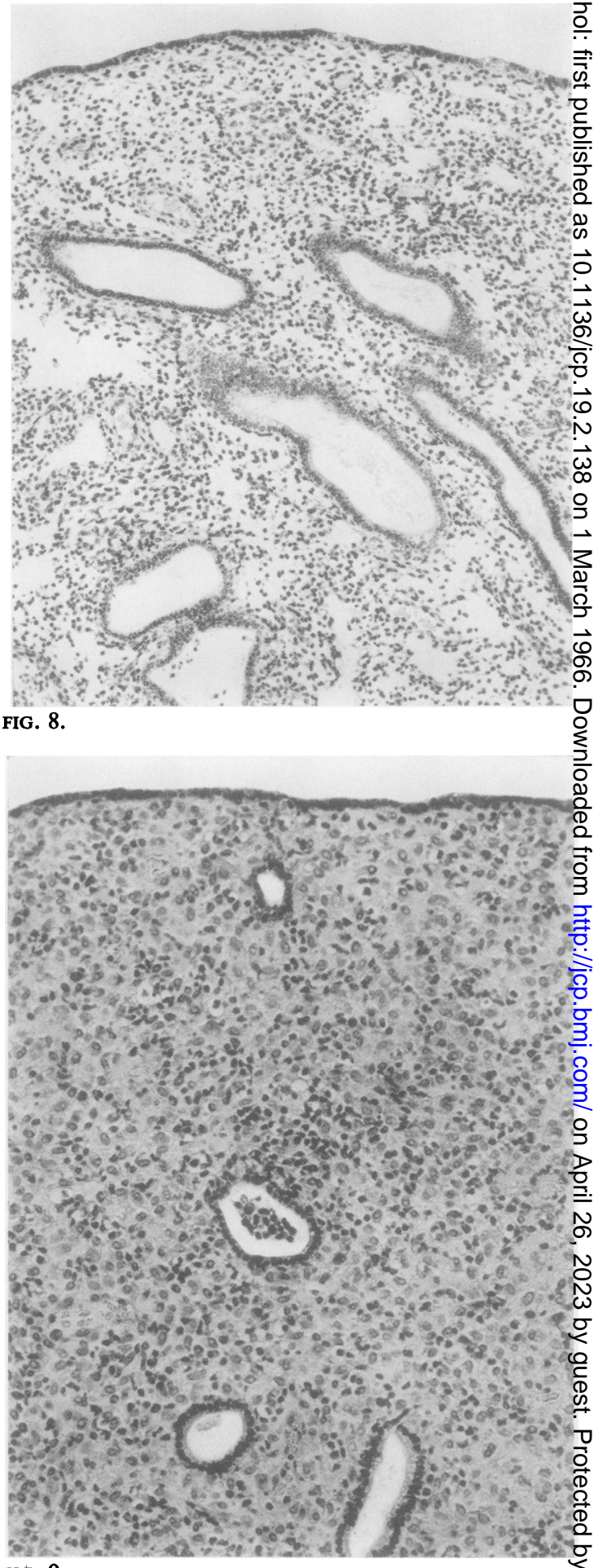

FIG. 9. 
The configuration of the endometrium closely resembles that produced by norethynodrel at a 2.5 mg. dose level, exhibiting less frequent and less intense predecidual response and a lesser degree of venular ectasia than at $10 \mathrm{mg}$. and $5 \mathrm{mg}$. dose levels.

WY-3707 The molecular structure of this 19-nor steroid is closely related to norethindrone. When given at $5 \mathrm{mg}$. daily without added oestrogen for 20 days, most of the biopsies on or about the 25th day of the cycle show a variable degree of regressing glandular secretion, variation being considerable and unpredictable from place to place within the same biopsy (Figs. 8 and 9.) A predecidual reaction is present in about half of the specimens; when present, it is usually weak and focal, appearing in some subjects as early as $\mathbf{1 0}$ days after medication was begun, but not at all in others. In an occasional instance the predecidual reaction is intense, but patchily distributed; the glands within such foci are small and exhausted of secretory activity. In the remaining half of the specimens the stroma is inert and of the naked nucleus type, showing varying degrees of cellular compaction. Spiral arterioles are developed to some extent in about one-thirds of the specimens; no abnormal venules are encountered.

When WY-3707 is given at an $0.5 \mathrm{mg}$. daily dose with $0.05 \mathrm{mg}$. of ethinyl oestradiol for 20 days, the structure of the endometrium is surprisingly uniform. In almost every instance the endometrial glands are of small calibre, lined by a low columnar to cuboidal epithelium without mitoses or secretion, and embedded in a loose, inert stroma (Figs. 10 and 11). Traces of a weak predecidual reaction are present in fewer than $10 \%$ of cases; when present, the predecidual reaction is either weak and diffuse or else in the form of small, relatively discrete plaques just beneath the surface epithelium. Development of spiral arterioles is uniformly suppressed. Ectatic venules are infrequent, and, when present, not dilated to any pronounced degree.

MEDROXYPROGESTERONE This derivative of $17-\alpha$ acetoxyprogesterone was given as its acetate in doses of $10 \mathrm{mg}$. and $5 \mathrm{mg}$. daily along with $0.05 \mathrm{mg}$. of ethinyl oestradiol (Provest); its effects on the endometrium have been reported (Borushek, Abell, Smith, and Gold, 1963; Roland, and Ober, 1963). When given in cyclic combined regimens, the usual precocious glandular secretion is seen in biopsies taken after five days of medication. Secretion regresses rapidly and gland development is arrested. After about 15 days of medication, a predecidual reaction appears to some extent in most subjects, approximately in proportion to the daily dose. Patients receiving $10 \mathrm{mg}$. daily tend to develop predecidual

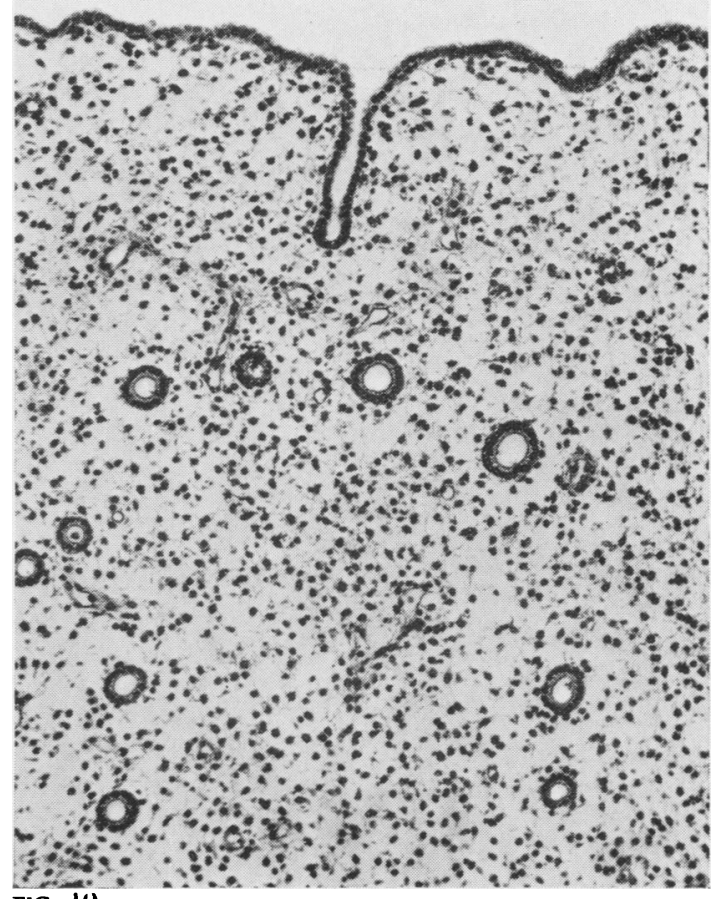

FIG. 10 .

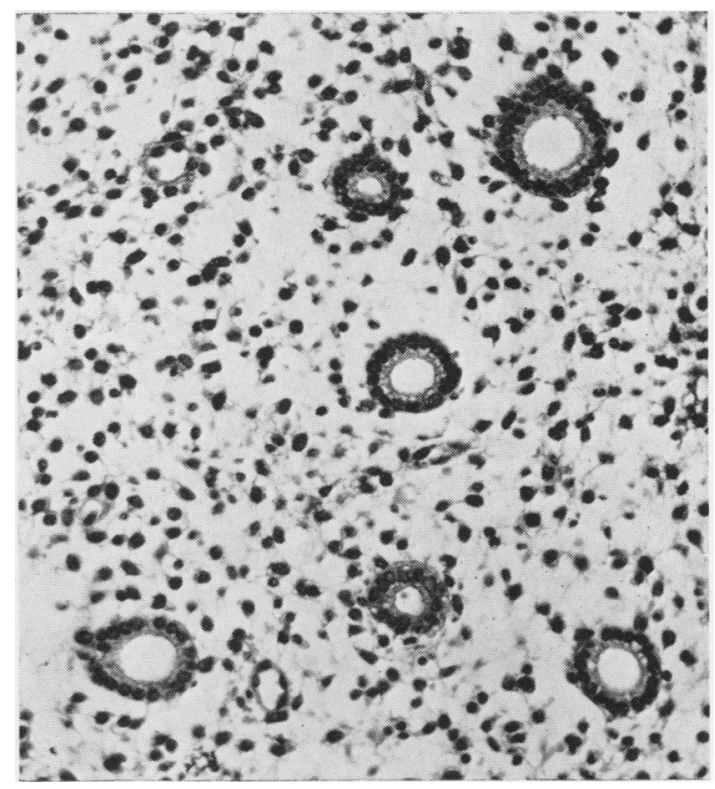

FIG. 11.

FIGS. 10 and 11. Endometrial biopsy after $W Y-3707$, $0.5 \mathrm{mg}$., with ethynil oestradiol, $0.05 \mathrm{mg}$. daily, for 20 days, showing small tubular glands lined by a low epithelium in a naked nucleus stroma with no development of spiral arterioles (haematoxylin and eosin $\times 100$ ), and (Fig. 11) detail of Fig. 10 (haematoxylin and eosin $\times 400$ ). 


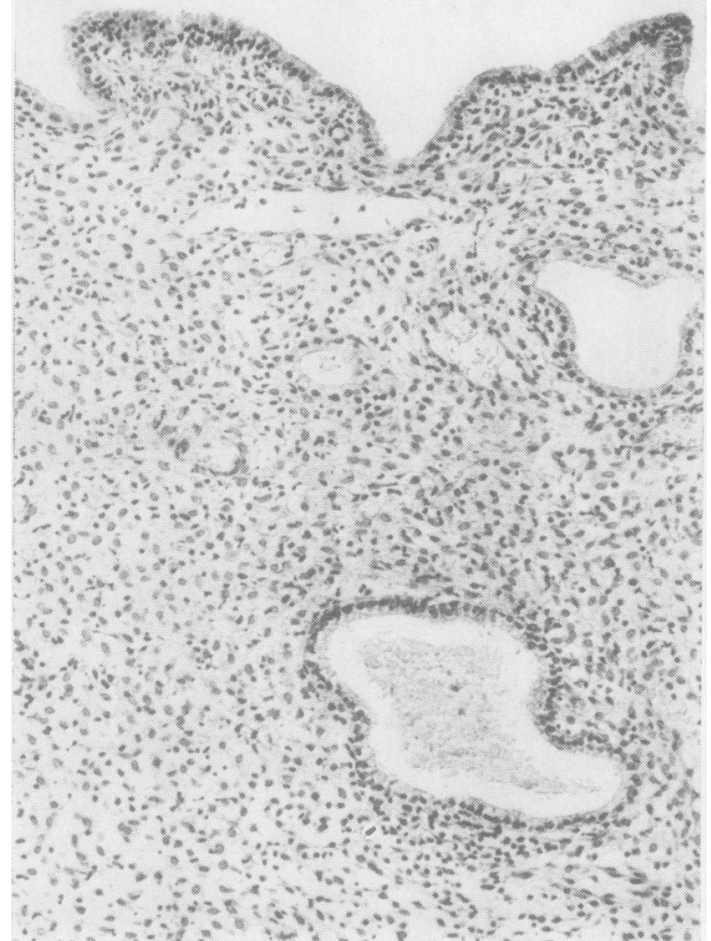

FIG. 12.

FIG. 12. Endometrial biopsy after medroxyprogesterone acetate $10 \mathrm{mg}$. with ethinyl oestradiol $0.05 \mathrm{mg}$. daily for 20 days showing a gland with regressing secretion, a weak predecidual response, and an abnormal vascular pattern. (Haematoxylin and eosin $\times 100$.)

FIG. 13. Endometrial biopsy after medroxyprogesterone acetate $5 \mathrm{mg}$. with ethinyl oestradiol $0.05 \mathrm{mg}$. daily for 20 days showing hyperinvolution of glands and a more intense predecidual reaction than in Fig. 12 the subject of which received twice the dose. (Haematoxylin and eosin $\times 100$.)

FIG. 14. Endometrial biopsy after medroxyprogesterone acetate $10 \mathrm{mg}$. with ethinyl oestradiol $0.05 \mathrm{mg}$. daily for 20 days showing detail of a very small gland and an intense predecidual reaction with increased Körnchenzellen. (Haematoxylin and eosin $\times 400$.)

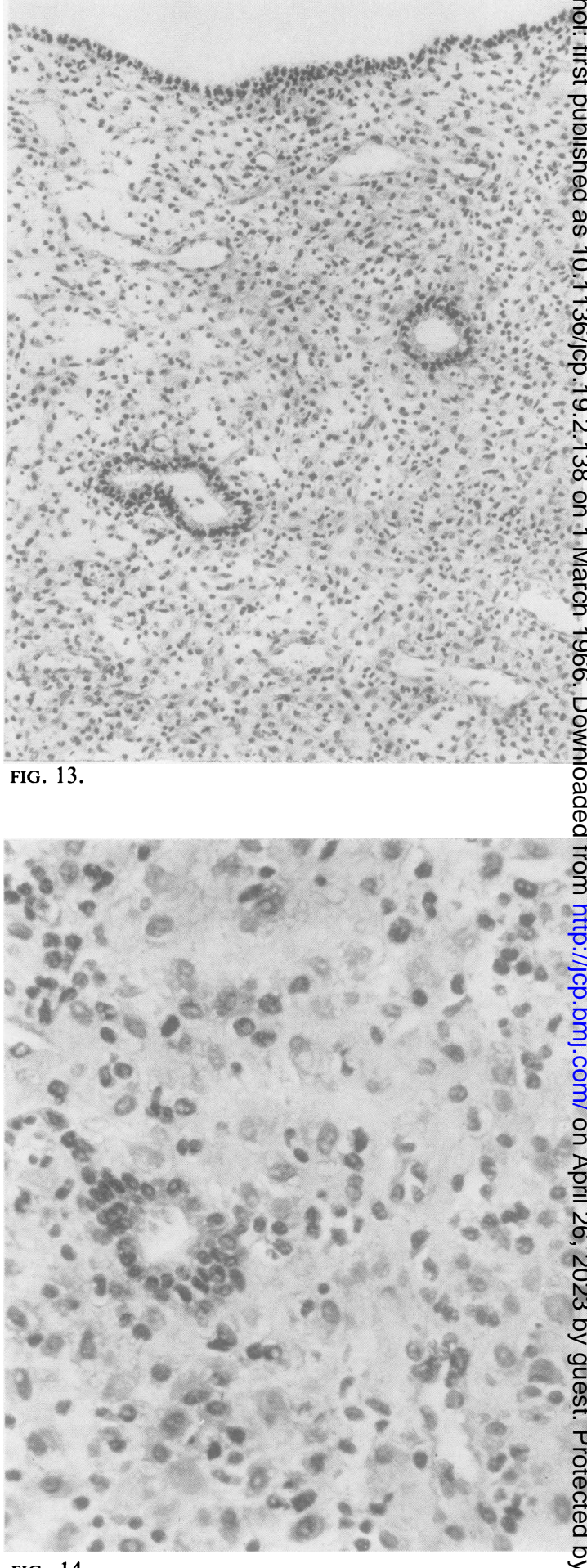

FIG. 14 . 


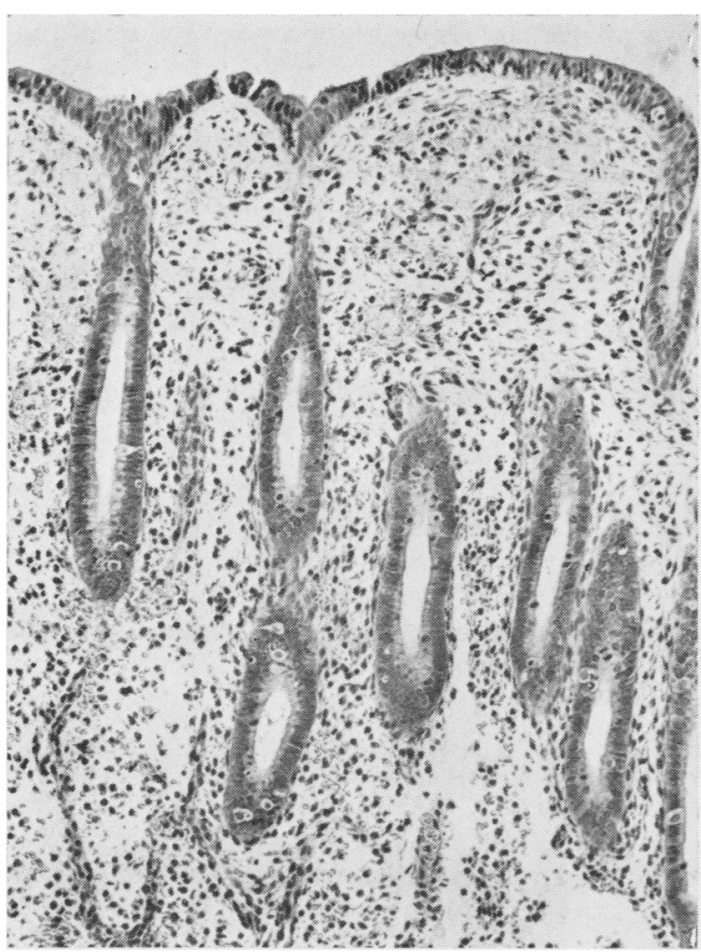

FIG. 15. Endometrial biopsy after mestranol $0.08 \mathrm{mg}$. daily for five days showing straight tubular glands with many mitoses in a stroma of average cellularity. (Haematoxylin and eosin $\times$ 100.)

response earlier and to a greater degree than those receiving $5 \mathrm{mg}$. daily, as gauged by biopsies taken after 20 days of medication. However, the degree of predecidual response is rarely so great as with norethynodrel. Development of spiral arterioles is uniformly inhibited. Dilated venules are present in biopsies after 20 days of treatment in about 20 to $25 \%$ of subjects, i.e., less frequently and to a lesser degree than with norethynodrel (Figs. 12, 13, and 14).

ChLORAMADINONE This derivative of $17-\alpha$-acetoxyprogesterone was also given as its acetate in doses of $2 \mathrm{mg}$. daily with $0.08 \mathrm{mg}$. of mestranot. Maqueo, Perez-Vega, Goldzieher, Martinez-Manautou, and Rudel (1963) and Rice-Wray, Arzada-Rosell, Maqueo, and Goldzieher (1963) have shown that when given in a cyclic combined regimen, the endometrial pattern after $\mathbf{2 0}$ days is that of small tubular glands in an inert stroma without developed arterioles. Our observations as well as those of others (Goldzieher, Becerra, Gual, Livingston, Maqueo, Moses, and Tietze 1964) are based on cyclic sequential medication in which oestrogen is given for 10 days, starting on the fifth day of the cycle, followed

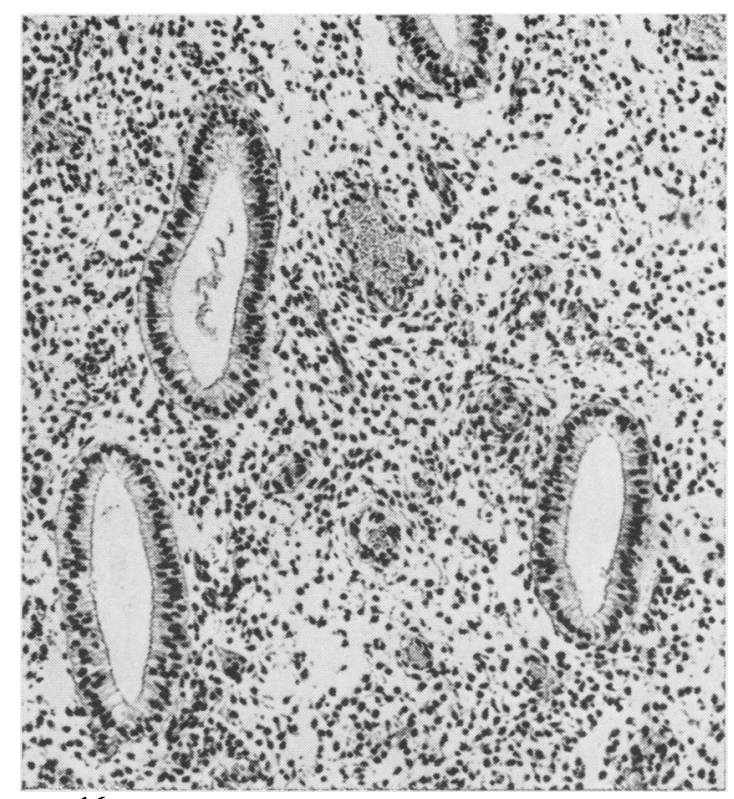
FIG. 16.

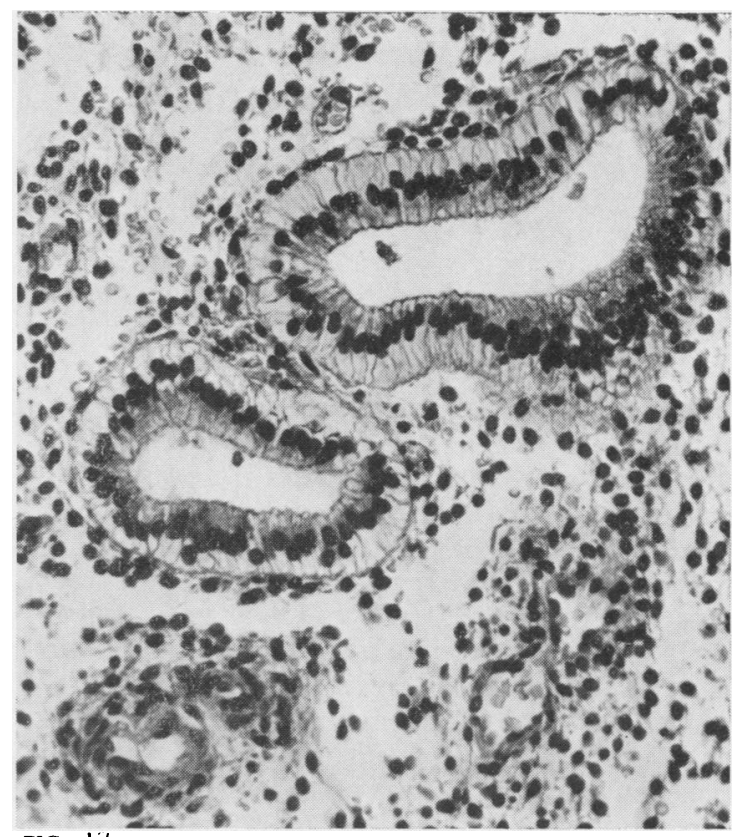

FIG. $1 \%$.

FIGs. 16 and 17. Endometrial biopsy after mestranol, $0.08 \mathrm{mg}$. daily for 10 days, followed by chloradmione, 2.0 mg. daily for 10 days, in sequence with mestranol dosage maintained, showing glands with subnuclear and supranuclear secretory vacuoles in naked nucleus stroma. Fourth cycle. Pattern is congruent with a normal secretory endometrium on the 18th day (haematoxylin and eosin $\times 100$ ). Fifth consecutive cycle of sequential mestranol and chlormadione showing detail (FIG. 17) of secreting glands $(\times 400)$. 


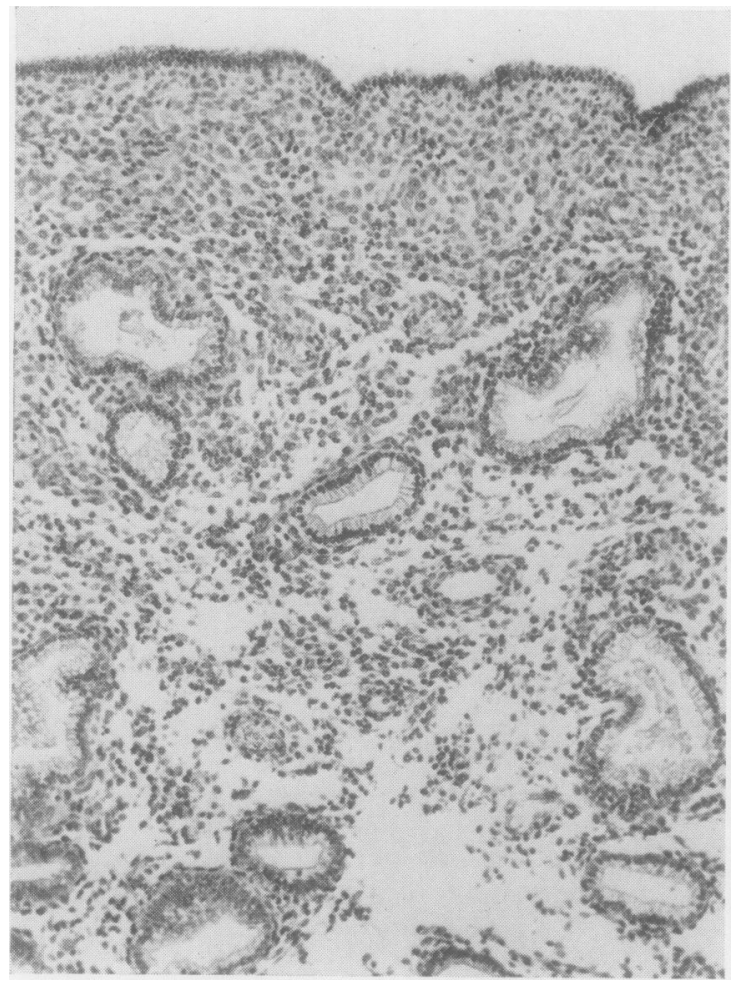

FIG. 18. Endometrial biopsy on day 27, three days after sequential mestranol and chlormadione regimen ended, showing regression of glandular secretion, a thin layer of predecidua underneath the surface epithelium, and no development of spiral arterioles.

by administration of progestagen with oestrogen for the next 10 to 11 days. Biopsies taken during mestranol administration without progestagen display the features of unopposed oetrogen: straight, tubular, non-secreting glands with variable mitotic activity in an indifferent stroma without unusual vascular pattern (Fig. 15). Biopsies taken on or about the 25th day of the cycle after 10 days of chlormadinone show, for the most part, the configuration of a normal secretory endometrium about five or six days less advanced than anticipated for the day of the cycle on which biopsy was performed. For the most part the pattern is that associated with the 17-to-19day pattern, slightly tortuous glands lined by tall columnar epithelium with prominent subnuclear and supranuclear vacuoles (Figs. 16 and 17). In some specimens products of secretion had been discharged into the glandular lumina. In a minority of specimens the configuration is that of a mucosa with regressing glandular secretion and a naked nucleus stroma which could not be assigned a chronological value in terms of conventional 'dating' schemes and was classified as 'regressing secretory endometrium undatable'. In four of 55 biopsies the configuration. could be assigned a pattern date of 23 days op beyond. A weak predecidual reaction was present io the stroma of these specimens in the form of a thi layer of plumper cells just beneath the surface epithelium (Fig. 18). In two of these specimens there was partial development of spiral arterioles. Dilated venules were not present in any specimen.

\section{DISCUSSION}

In the normal menstrual cycle secretary vacuoles appear in endometrial glands approximately two. days after the estimated time of ovulation. Likewise when Ehrmann, McKelvey, and Hertig (1961) explanted proliferative phase endometrium into steroid-free culture medium, similar secretory vacuo oles appeared no earlier than $\mathbf{4 8}$ hours after explantation. The hypothesis was advanced that the role of progesterone in endometrial gland secretion may be indirect rather than direct. Its behaviour in this phenomenon may be a function of its anti-oestroce genic action, viz., to neutralize the oestrogen whici inhibits the enzyme-controlled rate of synthesis of glycogen, glycoprotein, and mucopolysaccharide in glandular epithelium. In anovulatory cycles unop posed oestrogen blocks gland secretion quantitatively so that vacuoles are not formed, albeit small dropletso of secretion may be demonstrable. Although endo metrial gland cells contain the intracellular organelo les and enzymes which provide the necessary preconditions for secretion, progesterone does not stimulate them directly and its addition in vitro is not a necessary condition for visible secretory effects to develop. Presumably, failure to secrete during the oestrogen-controlled regenerating phase of the cycle depends upon oestrogen damping.

When secretory vacuoles develop in endometria $\bar{B}$ glands within five days after cyclic combined progestagen-oestrogen medication, the effect is readily explained by oestrogen priming and con은 comitant progestagen interference with the particulañ relation of the oestrogen to the intracellular apparatus. A corroborating, comparable effect is seen in cyclic sequential regimens, the difference being ant approximate five-day delay in the appearance of secretory vacuoles. The critical difference between combined and sequential regimens is the time in the cycle at which the progestagen is applied. In theory under sequential medication, ovulation is inhibitedo by oestrogen given for 10 days during the first hal $\overline{0}$ of the cycle. Previous observations (Sturgis and Albright, 1940; Lyon, 1943) have shown that ovula-ه tion can be inhibited for several consecutive cycles byo moderate doses of oestrogen alone. However, two 
disadvantages are stated to occur under these conditions, namely, 'escape' ovulation and abnormal endometrial morphology. When synthetic progestagen is added sequentially following oestrogen inhibition of ovulation, endometrial morphology assumes a more normal configuration, and after medication is discontinued, the bleeding occurs because both progestagen and oestrogen are withdrawn rather than as simple oestrogen withdrawal bleeding. To some extent, cyclic sequential regimens simulate the steroid pattern of a normal cycle, the difference being that in the untreated subject the corpus luteum is still in the stage of vascularization 48 hours after estimated ovulation and presumably progesterone biosynthesis is not at its peak, as urinary pregnanediol values are not maximal. Sequential regimens differ in that the level of progestagen is increased abruptly rather than gradually over a five-day interval.

When used in cyclic combined regimens, only slight differences are seen in endometrial morphology between 19-nor steroids and 17- $\alpha$-acetoxyprogesterone derivatives. With both classes of steroid there is precocious glandular secretion which regresses rapidly. With high and medium dosage (10 $\mathrm{mg}$. and $5 \mathrm{mg}$.) a predecidual reaction occurs in the stroma of most subjects, somewhat more intense with $10 \mathrm{mg}$. than $5 \mathrm{mg}$., somewhat more intense with 19-nor steroids than with 17- $a$-acetoxyprogesterone derviatives, but qualitatively similar. Ectasia of venules is less pronounced with 17- $a$-acetoxyprogesterone derivatives than with 19-nor steroids, and this may have some relation to the frequency of breakthrough bleeding. In lower doses $(0.5$ to $2.0 \mathrm{mg}$.) both classes of steroid, when combined with oestrogen, produce small tubular, inactive glands and an inert stroma with minimal predecidual change and only occasional venular ectasia after 20 days of medication.

In all instances, except when a progestagen is given without oestrogen, there is essentially complete suppression of the development of spiral arterioles. The vasculature of progestagen-oestrogen treated endometria consists of a network of tiny, inconspicuous capillaries. In normal, untreated endo- metria the initial site of predecidual transformation is in the form of collarettes around developing spiral arterioles, beginning on the twenty-third day and then becoming confluent. The spatial distribution of predecidual response in treated endometria, either as weak, diffuse changes or as focal plaques or layers just beneath the surface epithelium, is consonant with the hypothesis that progestational steroids diffuse from endothelial-lined channels, acting directly on the cytoplasm of stromal cells in topographic progression dependent upon their propinquity to the nearest vascular channel.

Successful maintenance of a nidated placenta depends in large measure upon the establishment of a direct connexion between maternal spiral arterioles and the intervillous space. Inhibition of spiral arterioles might serve to prevent successful placentation in those few cases in which ovulation escapes from exogenous steroid inhibition and fertilization occurs. It is supererogatory to rebut the argument that a fertilized ovum can implant on any surface, e.g., the mucosa of the oviduct or the pelvic peritoneum; clearly in such instances maintenance of a viable gestation is precarious.

\section{REFERENCES}

Borushek, S., Abell, M. R., Smith, L., and Gold, J. J. (1963). Int. J. Fertil., 8, 605.

Cronqvist, M., and Kullander, S. (1961). Acta obstet. gynec. scand., 40, 43.

Ehrmann, R. L., McKelvey, H. A., and Hertig, A. T. (1961). Obstet. and Gynec., 17, 416.

Goldzieher, J. W., Becerra, C., Gual, C., Livingston, N. B., Jr., Maqueo, M., Moses, L. E., and Tietze, C. (1964). Amer. J. Obstet. Gynec., 90, 404.

Lyon, R. A. (1943). Surg. Gynec. Obstet., 77, 657.

Maqueo, M., Perez-Vega, E., Goldzieher, J. W., Martinez-Manautou, J., and Rudel, H. (1963). Amer. J. Obstet. Gynec., 85, 427.

Morley, F. (1965). In preparation.

Rice-Wray, E., Aranda-Rosell, A., Maqueo, M., and Goldzieher, J. W. (1963). Amer. J. Obstet. Gynec., 87, 429.

Roland, M., and Ober, W. B. (1963). Int. J. Fertil., 8. 619.

-, Clyman, M. J., Decker, A., and Ober, W. B. (1964). Fertil. and Steril., 15, 143.

—-, Decker, A., Clyman, M. J., and Ober, W. B. (1965). Ibid., In press.

Ryan, G. M., Jr., Craig, J., and Reid, D. E. (1964). Amer. J. Obstet. Gynec., 90, 715.

Sturgis, S. H., and Albright, F. (1940). Endocrinology, 26. 68. 